\title{
Avaliação da vulnerabilidade ao risco de contaminação dos recursos hídricos subterrâneos do município de Piratini-RS
}

\author{
Vulnerability assessment of the risk of contamination of groundwater resources in the city of Piratini-RS \\ Cibelle Machado Carvalho', Najila Souza Rocha², Denise Silva Nunes ${ }^{3}$, Rafael Cabral Cruz ${ }^{4}$ \\ 1,2Mestrandas no Programa de Pós-Graduação em Engenharia Ambiental da Universidade Federal de Santa Maria, RS,Brasil \\ ${ }^{3}$ Mestranda do Programa de Pós-Graduação em Direito da Universidade Federal de Santa Maria, \\ ${ }^{4}$ Oceanógrafo. Professor Dr. da Universidade Federal do Pampa - UNIPAMPA.
}

\begin{abstract}
Resumo
A sociedade tem sido marcada pela preocupação com as crescentes degradações dos recursos hídricos. Em frente a esse cenário, a avaliação da vulnerabilidade dos aquíferos é uma ferramenta eficaz para metodologias de gestão de recursos hídricos. O uso desses recursos naturais, no entanto, ainda necessita de estratégias mais conscientes por parte dos atores locais. Qualquer ação de modificação de tais práticas requer conhecimento sobre a realidade onde ocorrem visando estratégias de educação ambiental que promovam modificações no comportamento dos atores sobre o meio onde estão inseridos. Partindo desse pressuposto, o objetivo geral do presente trabalho é mapear a vulnerabilidade das águas subterrâneas do município de Piratini, localizada no estado do Rio Grande do Sul, sul do Brasil, situado na Serra do Sudeste, a montante da bacia hidrográfica do Rio Camaquã. Utilizou-se como ferramenta o método GOD, adaptado para situações brasileiras. Elaborouse um banco de dados no software Microsoft Excel relativos aos 12 poços que continham todas as informações fundamentais para adaptar ao método de grau de confinamento, meio aquífero e profundidade do nível da água. Para análise das variáveis foram gerados cartogramas a partir do programa Surfer 8 do grau de vulnerabilidade na região estudada e no ArcGis 10 através do método IDW que corresponde à interpolação entre cada ponto como uma influência local, diminuindo à medida que a distância entre os pontos aumenta. No software Surfer 8 os resultados apontaram que a maioria dos poços apresenta vulnerabilidade insignificante e baixa, e no ArcGis 9.3 todos os poços apresentaram baixa vulnerabilidade. No entanto são resultados simplificados, em uma região complexa como a Serra do Sudeste, na qual, há poucos poços tubulares, devido a sua geologia e muitas aflorações e nascentes utilizadas como abastecimento humano.
\end{abstract}

Palavras-chave: vulnerabilidade, GOD, recurso hídrico.

\begin{abstract}
The society has been marked by concern over the increasing degradation of water resources. Considering this scenario, the assessment of vulnerability of aquifers is an effective tool for methodologies of Water Resource Management. The use of these natural resources, however, still requires more conscious strategies by local actors. Any action of modifying such practices requires knowledge about the reality aiming environmental education strategies that promote changes in the behavior of the actors on the environment where they live. Based on this assumption, the general objective of this study is to map the vulnerability of groundwater in Piratini city, located in Rio Grande do Sul state, South of Brazil, situated in the Serra of Southeast, near basin of Camaquã river. It was used GOD method as the tool adapted for Brazil situations. It was ellaborated a database in the Microsoft Excel software for the 12 wells that contained all the essential information to adapt to the method of degree of confinement, aquifer environment and deepth of water level. To analyze the variables cartograms were generated from Surfer 8 program of the degree of vulnerability in the study area and in ArcGIS 10 program through the IDW method that corresponds to the interpolation between each point as a local influence, decreasing as that the distance between the points increases. In Surfer 8 software the results indicated that most of the wells shows insignificant and low vulnerability, and in ArcGIS 9.3 all wells had low vulnerability. However these results are simplified in a complex area such as the Serra of Southeast, where there are few wells due to its geology and many outcrops and springs used as human supply.
\end{abstract}

Keywords: vulnerability; GOD; water resource 


\section{INTRODUÇÃO}

O município de Piratini está localizado na microrregião da Serra do Sudeste e na mesorregião do Sudeste Rio-Grandense do Estado do Rio Grande do Sul. É constituído pelas cabeceiras do território do Alto Camaquã, localizada, na região a montante da Bacia Hidrográfica do Rio Camaquã (Figura 1).

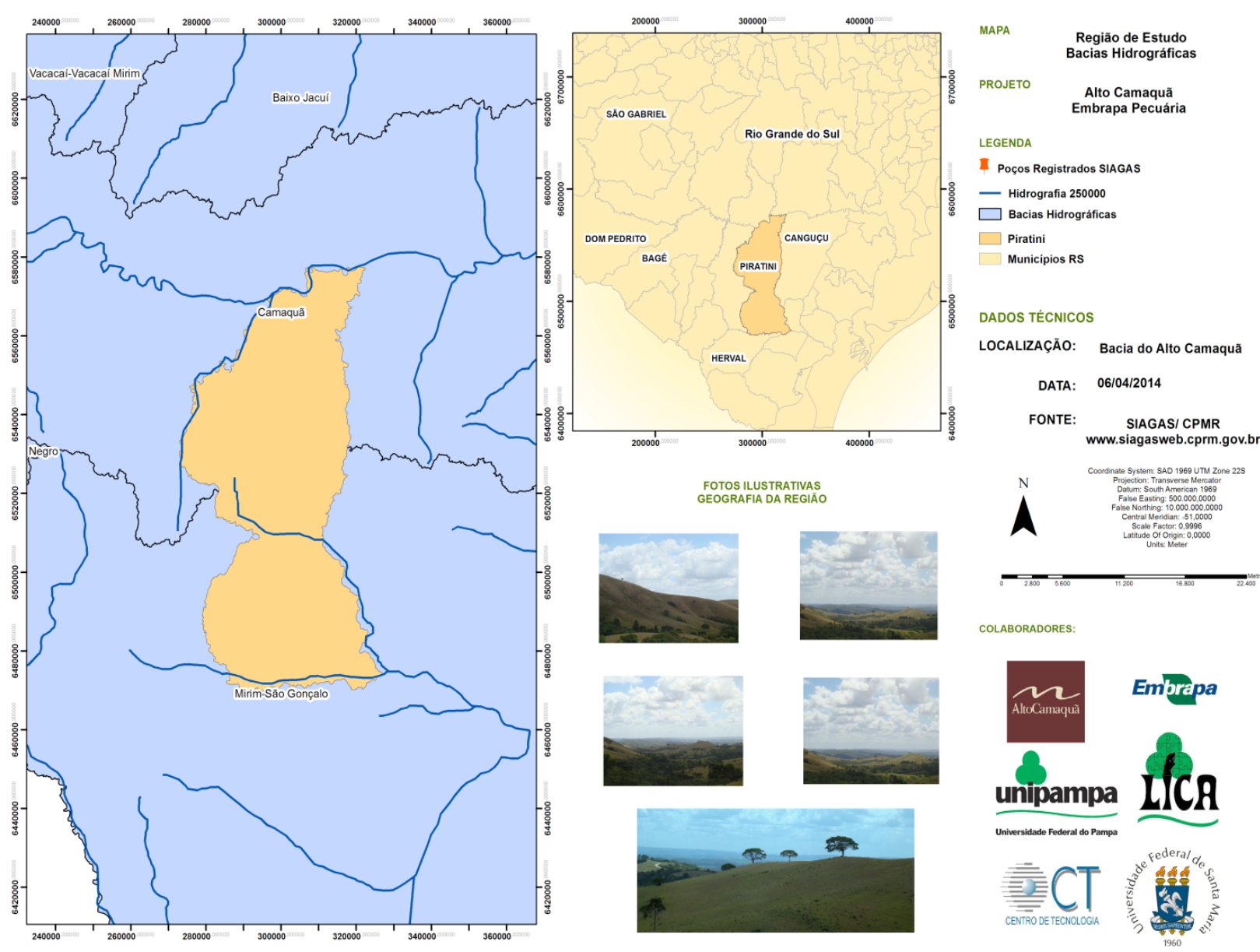

Figura 1: Localização município Piratini-RS. Fonte: IBGE 2014, elaborado pelo autor.

Essa região é composta por uma notória beleza do bioma Pampa, com aflorações rochosas, vales, plantas endêmicas e com pouca degradação ambiental (TRINDADE et al., 2010).

De acordo com o censo de 2010 do Instituto Brasileiro de Geografia e Estatística (IBGE) a população do Município de Piratini era de 19.814 habitantes. A área do município totaliza-se em $3.561,5 \mathrm{~km}^{2}$. O abastecimento na área urbana é oferecido pela Companhia Rio-Grandense de Saneamento (CORSAN).

No mundo inteiro, os aquíferos estão sob perigo cada vez maior de contaminação em decorrência da urbanização, do desenvolvimento industrial, das atividades agrícolas e das empresas de mineração (FOSTER et al., 2010). Em Piratini não seria diferente, visto que a sua economia é baseada principalmente na agricultura, pecuária, extração de pedras para exportação, pedras de revestimento e produção de cimento.

E uma área de grande complexidade geológica, as formações são compostas por rochas ígneas e metamórficas (Complexo Metamórfico Porongos) arenitos, siltitos e argilitos (Sanga do Cabral) e areia grossa a fina e sedimento inconsolidado, siltítico-argiloso (Dépositos Aluviais) (MACHADO, 1998; CPRM, 2005).

Partindo desse pressuposto, as formações influenciam no sistema de armazenamento de água no solo e em suas características de afloramento. Hidrogeologicamente existem dois tipos de formação na área em estudo: o Sistema Aquífero Embasamento Cristalino II e o Sistema Aquífero Embasa- 
mento Cristalino III. O primeiro compreende rochas graníticas, gnáissicas, andesitos, xistos, filitos e calcários metamorfizados, afetadas por fraturamentos e falhas, classificado como aquífero limitado de baixa possibilidade para água subterrânea em rochas com porosidade intergranular ou por fraturas (CPRM, 2005) e o segundo não apresenta fraturas interconectadas e sua condição topográfica inviabiliza a perfuração de poços tubulares mesmo para baixas vazões. São sistemas aquíferos praticamente improdutivos em rochas com porosidade intergranular ou por fraturas (CPRM, op. cit.).

A natureza e a distribuição dos aquíferos são controladas pela litologia, estratigrafia e estrutura das juntas, falhas e dobras geológicas, portanto, o conhecimento das características geológicas de uma região é a base para compreensão da distribuição espacial dos aquíferos (MANOEL FILHO, 2000).

Essa região não chegou a se transformar através da implantação em larga escala da agricultura tradicional nem da agricultura moderna, mantendo-se, assim, com uma alta dependência dos recursos naturais (TRINDADE et al., 2010).

Em contrapartida, já está sendo implantado o modelo de monocultura de árvores exóticas e de soja, muitas vezes sem respeitar as restrições recomendadas pelos órgãos ambientais responsáveis.

No Alto Camaquã, principalmente no distrito do Barrocão, localizado no munícipio de Piratini, fica evidente que a água constitui importante fator de restrição. A irregularidade das precipitações, dificuldades de captação, distribuição e uso da água, supressão da vegetação, depósito de lixo doméstico em zonas de recarga e o uso de nascentes como bebedouros de animais estão entre os principais problemas identificados. A qualidade e quantidade da água nas nascentes da bacia hidrográfica estão sendo alteradas por fatores de ação antrópica (CARVALHO, 2012).

Há premências em estudos desta natureza, além de relevância acadêmica, política, ambiental e social. Há necessidade de se determinar a sensibilidade do aquífero à contaminação, principalmente aos danos causados aos recursos hídricos, visto que a população rural predominantemente utiliza água de nascentes/cacimba, oriunda do abastecimento subterrâneo.

Tratando-se de recursos subterrâneos, a preservação requer um nível de informação elevado, pois eles não estão visíveis, tornando-os muito mais vulneráveis. Como forma de conservação e uso adequado dos recursos hídricos subterrâneos, as avaliações e o mapeamento da vulnerabilidade natural indicam quais as áreas de maior ou menor suscetibilidade do aquífero à contaminação (LÖBLER et al., 2013).

Partindo desse pressuposto, o objetivo deste trabalho foi mapear a vulnerabilidade à contaminação dos poços de água subterrânea do município de Piratini/RS. Foram utilizados apenas os dados pré-existentes obtidos através do cadastro eletrônico de usuários de águas subterrâneas do Sistema de Informação de Águas Subterrâneas (SIAGAS) disponíveis no site da CPRM.

\section{MATERIAL E MÉTODO}

Realizou-se a organização do banco de dados dos poços cadastrados no munícipio (buscados no sítio da web do CPRM/SIAGAS). Utilizou-se como ferramenta de suporte o software Microsoft Excel, para acondicionar os seguintes parâmetros: número de poços, coordenadas UTM, nível dinâmico, formação, dados litológicos, vazão específica, profundidade final.

Dos 17 poços cadastrados, 12 foram selecionados (Figura 2) devido a apresentarem informações completas para análise através do método "GOD", desenvolvido por Foster \& Hirata (1988) e Foster et al. (2006).

O Método é assim chamado devido suas iniciais de origem inglesa, significando respectivamente Groundwater hydraulic confinement - grau de confinamento hidráulico, Overlaying strata - Ocorrência de substrato litológico, Depth to groundwater table - Distância da água, ou seja, profundidade do lençol freático ou teto do aquífero confinado.

O método GOD (Figura 3) é composto nas seguintes fases: G: Tipo de ocorrência da água subterrânea, onde os valores são obtidos em um intervalo variável de 0 a 1 . Procura-se identificar as condições do meio livre, confinado, semiconfinado; O: Classificação dos estratos acima da zona saturada do aquífero, em termos do grau de consolidação e do tipo de litologia penetradas pela captação. Esse parâmetro é variável numa faixa entre 0,3 e 1,0; e D: Determinação da profundidade do nível da água, que definirá o terceiro parâmetro, no intervalo de 0,4 a 1,0. Quanto maior a profundidade do nível da água, menor a nota atribuída ao parâmetro. Segundo Foster (2006), o índice de vulnerabilidade pode ser considerado em classes padronizadas: insignificante $(0$ a 0,1$)$, baixa $(0,1$ a 0,3$)$, média $(0,3$ a 


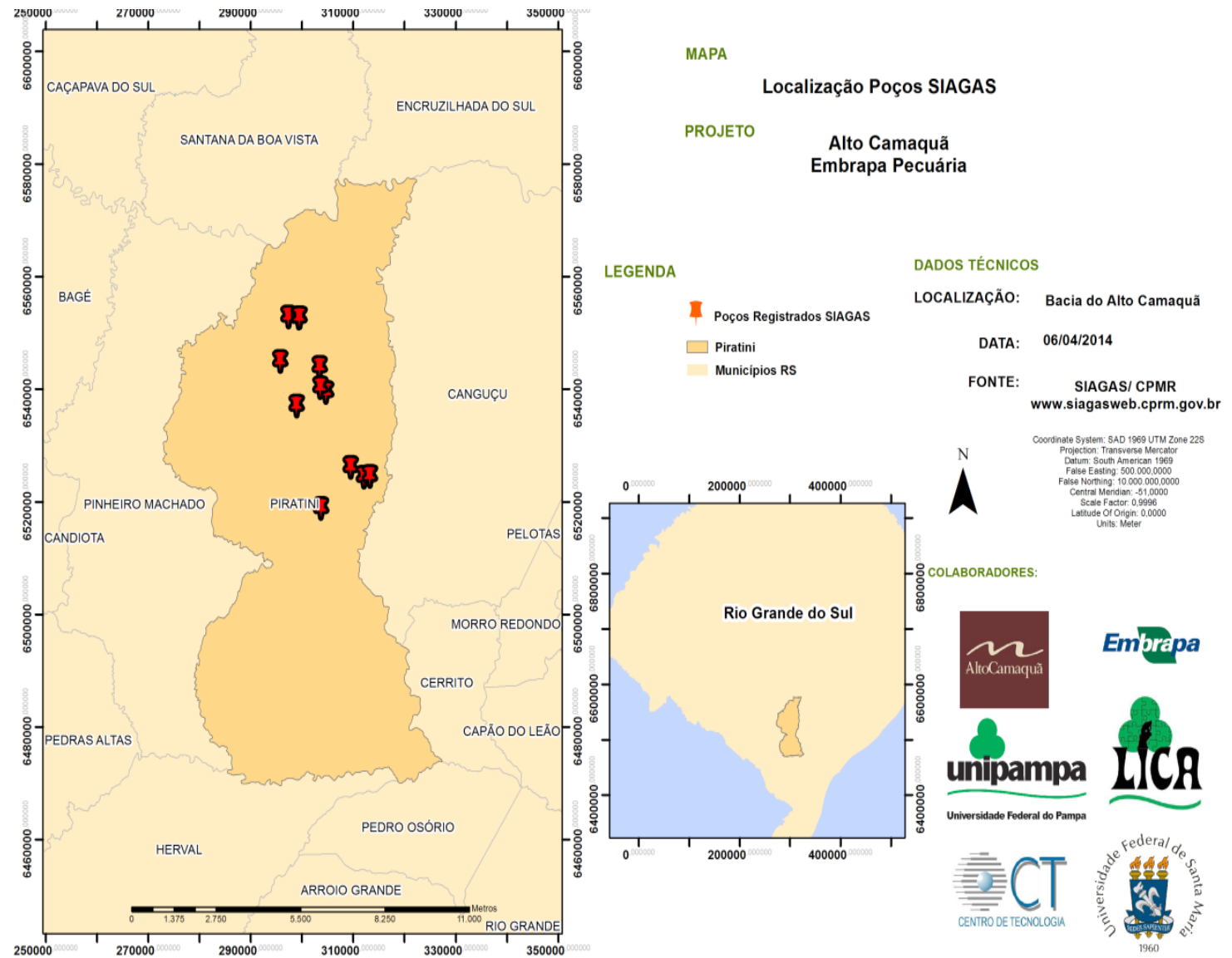

Figura 2: Mapa com localização do município e dos poços

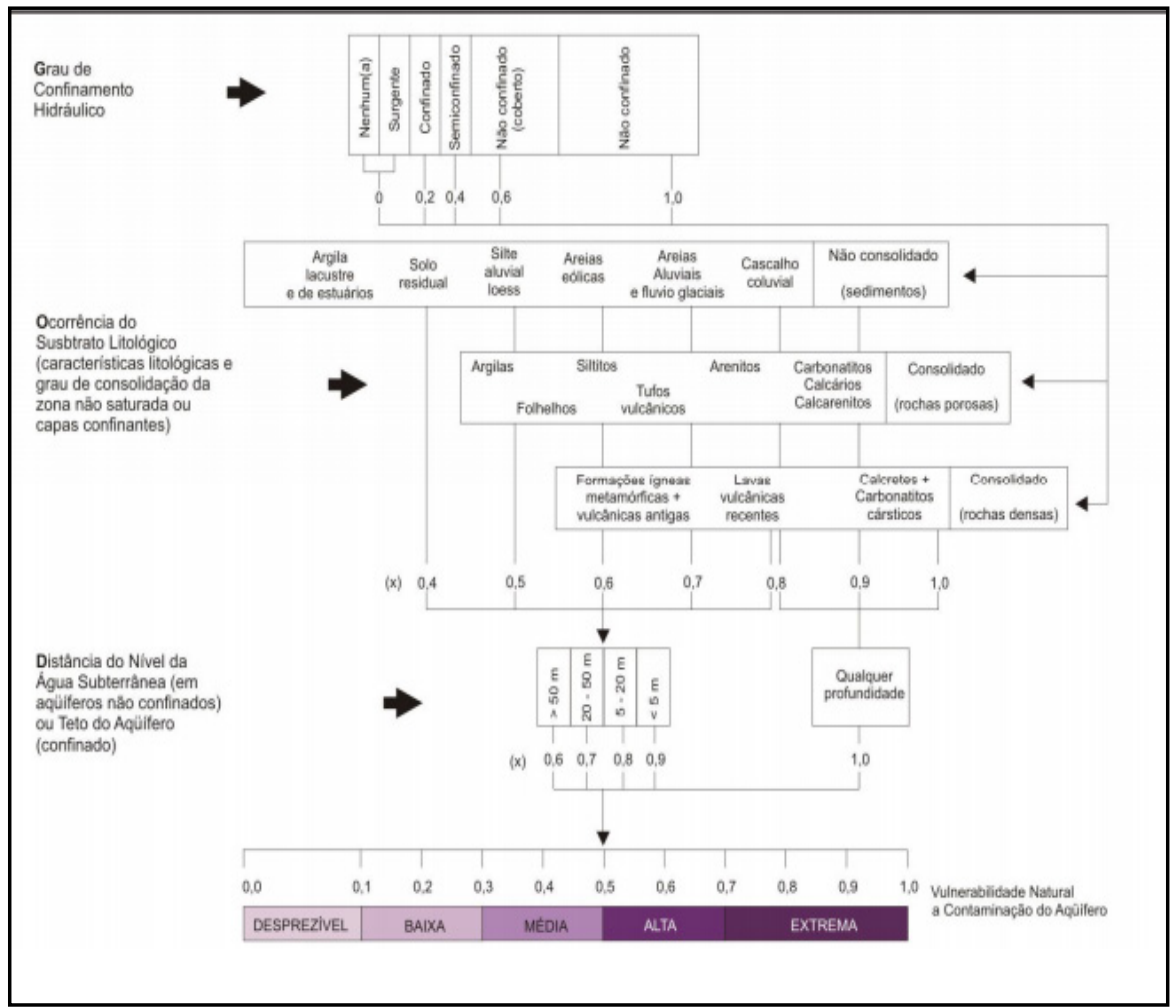

Figura 3: Modelo representativo do sistema GOD para avaliação da vulnerabilidade do aquífero à contaminação. Fonte: Adaptado de Foster e Hirata et al (1988) 
0,5), alta $(0,5$ a 0,7$)$ e extrema $(0,7$ a 1,0). Para a elaboração dos mapas foram utilizados os Softwares SURFER 8.0 e ArcGis 9.3.

No ArcGis 9.3, utilizou-se o método IDW que corresponde à interpolação entre cada ponto como uma influência local, diminuindo à medida que a distância entre os pontos aumenta. Em estudo realizado por Medeiros (2011), esse método apresentou valores mais próximos entre o dado observado e o medido. Segundo Wei e McGuinnes (1973), citado por Medeiros (2011), o uso de interpolador IQW é recomendado quando a variável a ser mapeada diminui com a distância na localização amostrada.

\section{RESULTADOS}

Os poços registrados estão presentes na parte central no município de Piratini $\backslash$ RS como mostra na Figura 2. Por esse motivo não é possível afirmar que todo o município possui os índices de vulnerabilidade indicados neste trabalho, ao mesmo tempo, isso também demonstra a necessidade de uma ampliação da base territorial coberta por dados de poços tubulares no município de Piratini. Com base nas variáveis disponíveis no SIAGAS, podem-se calcular os índices de vulnerabilidade descritos pelo método GOD, chegando-se aos seguintes resultados descritos na Figura 4.

\begin{tabular}{c|c|c|c|c|c|c|c} 
ponto & uso_agua & nivel_estatico & $\mathbf{G}$ & $\mathbf{O}$ & $\mathbf{D}$ & NOTA GOD & VULNERABILIDADE \\
\hline 4300000220 & Abastecimento urbano & 11.00 & 0,4 & 0,5 & 0,8 & 0,16 & Baixa \\
\hline 4300006576 & Abastecimento múltiplo & 22.75 & 0,4 & 0,5 & 0,7 & 0,14 & Insignificante \\
\hline 4300006577 & Abastecimento doméstico & 4.00 & 0,4 & 0,6 & 0,9 & 0,21 & Baixa \\
\hline 4300006578 & Abastecimento múltiplo & 6.00 & 0,4 & 0,6 & 0,8 & 0,192 & Baixa \\
\hline 4300006579 & Abastecimento múltiplo & 3.30 & 0,4 & 0,6 & 0,9 & 0,216 & Baixa \\
\hline 4300006897 & Abastecimento doméstico & 1.00 & 0,4 & 0,4 & 0,9 & 0,144 & Insignificante \\
\hline 4300006898 & não consta informação & 8.00 & 0,4 & 0,6 & 0,8 & 0,192 & Insignificante \\
\hline 4300006899 & Outros (lazer,etc.) & 6.00 & 0,4 & 0,6 & 0,8 & 0,19 & Insignificante \\
\hline 4300020536 & Abastecimento múltiplo & 3.21 & 0,4 & 0,6 & 0,9 & 0,21 & baixa \\
\hline 4300020537 & Doméstico/irrigação/animal & 9.10 & 0,4 & 0,7 & 0,8 & 0,224 & baixa \\
\hline 4300020538 & Abastecimento múltiplo & 0.38 & 0,4 & 0,6 & 0,9 & 0,216 & baixa \\
\hline 4300021429 & não consta informação & 6.59 & 0,4 & 0,6 & 0,8 & 0,192 & Insignificante \\
\hline
\end{tabular}

Figura 4: Índice de vulnerabilidade do aquífero à contaminação, com base nos 12 poços de captação do sistema "GOD" e o uso da água.

É importante perceber que a variável G (Grau de confinamento da água subterrânea) obteve o mesmo valor para todos os pontos, não demonstrando diferença. Sendo assim, é possível afirmar que as variações das vulnerabilidades dependem dos outros dois parâmetros.

A análise dos perfis geológicos dos poços pesquisados revelou a predominância de frações granulométricas: solo arenoso, argiloso, silte, granito e rochas intemperizadas. Com diferentes solos, diferentes graus de infiltração, conseguinte, diferentes graus de vulnerabilidade. No entanto, os arenitos e siltitos apresentam boa relação de porosidade, determinando uma maior facilidade de movimentação de contaminantes. Os materiais argilosos apresentam maior grau de vulnerabilidade, e os materiais arenosos menores. A predominância de classe insignificante e baixa deve-se a ocorrência de camadas argilosas impermeáveis, as quais protegem os aquíferos na região do estudo.

$\mathrm{Na}$ Figura 4, que apresenta os usos da água, observou-se que o principal uso do município de Piratini é o abastecimento múltiplo, no qual, incluem-se o abastecimento humano. A baixa faixa de 
variação do nível da água subterrânea (entre 1 até $30 \mathrm{~m}$ ) foi identificadas surgências (nascentes) na área estudada.

\subsection{Análise de Vulnerabilidade}

Após a coleta de dados, realizou-se um mapa descrevendo a fragilidade de cada ponto, a partir do nível estático (Figura 5). A média do município demonstrou que a vulnerabilidade referente à contaminação é insignificante a baixa, descrita conforme as Figura 2, 3, 4 e 5. O mapa de vulnerabilidade foi confeccionado a partir da sobreposição dos três mapas referentes aos parâmetros requeridos na metodologia "GOD". A variável G não apresentou diferença, sendo assim não será demonstrada na Figura 5 que ilustra separadamente os parâmetros dos poços. Após a realização da sobreposição, com a ferramenta do ArcToolBox> Math > Times que multiplica dois planos de informação em formato raster realizando a multiplicação "pixel a pixel", gerou-se um novo plano de informação onde o valor de cada pixel é o resultado desta multiplicação.

A Figura 6 representa o plano de informação resultante dessa operação, que é exatamente o mapa de vulnerabilidade, objetivo principal deste trabalho. No ArcGis, é possível visualizar que mesmo com uma vulnerabilidade baixa há diferenças dentro desse, demonstrando melhor as diferenças entre os poços. Esse software é então mais adequado para esse tipo de análise, por conseguinte, mostrandose uma melhor visualização das variáveis.
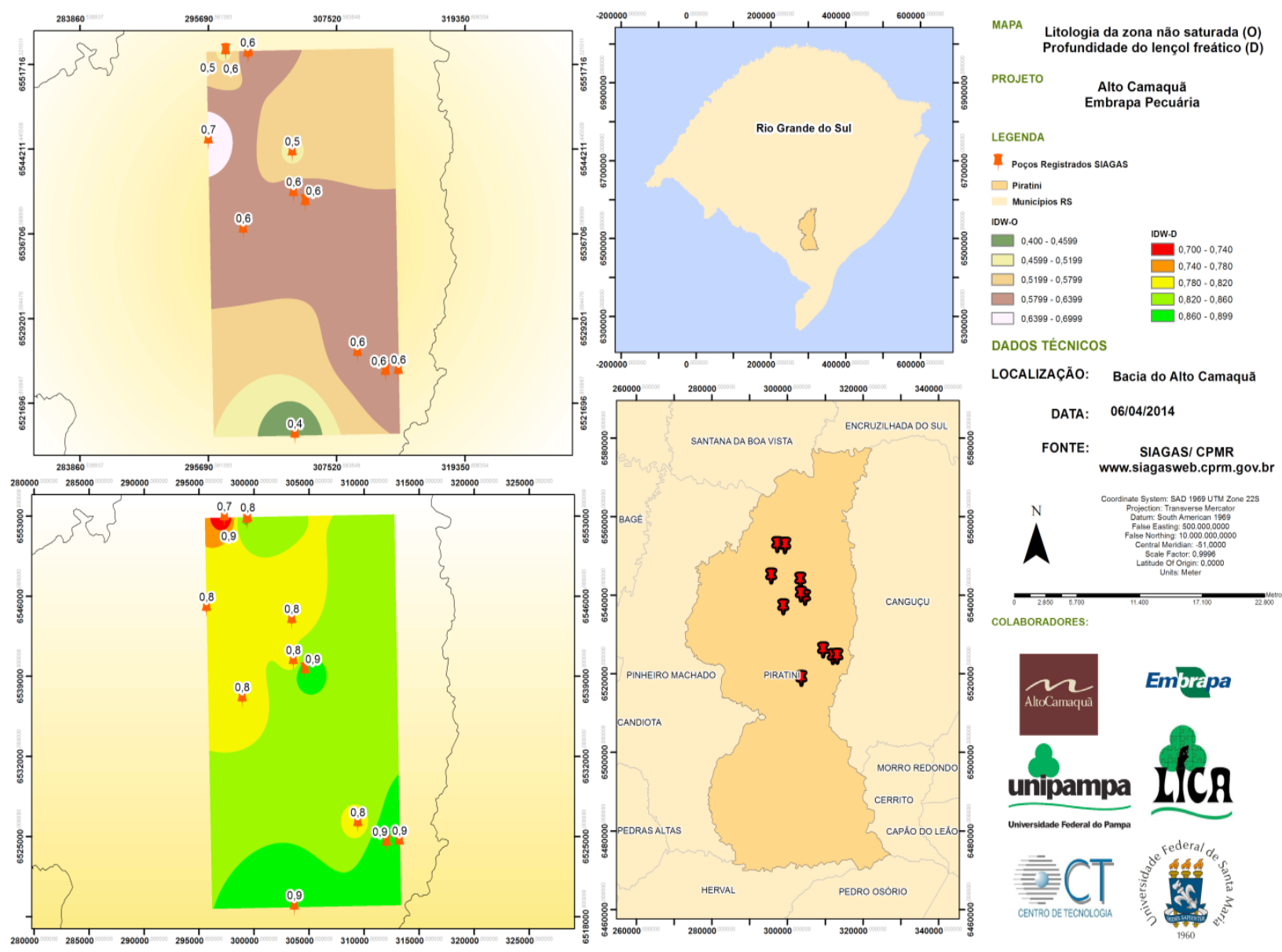

Figura 5: Mapa dos Parâmetros D e O, no software ArcGis 10 


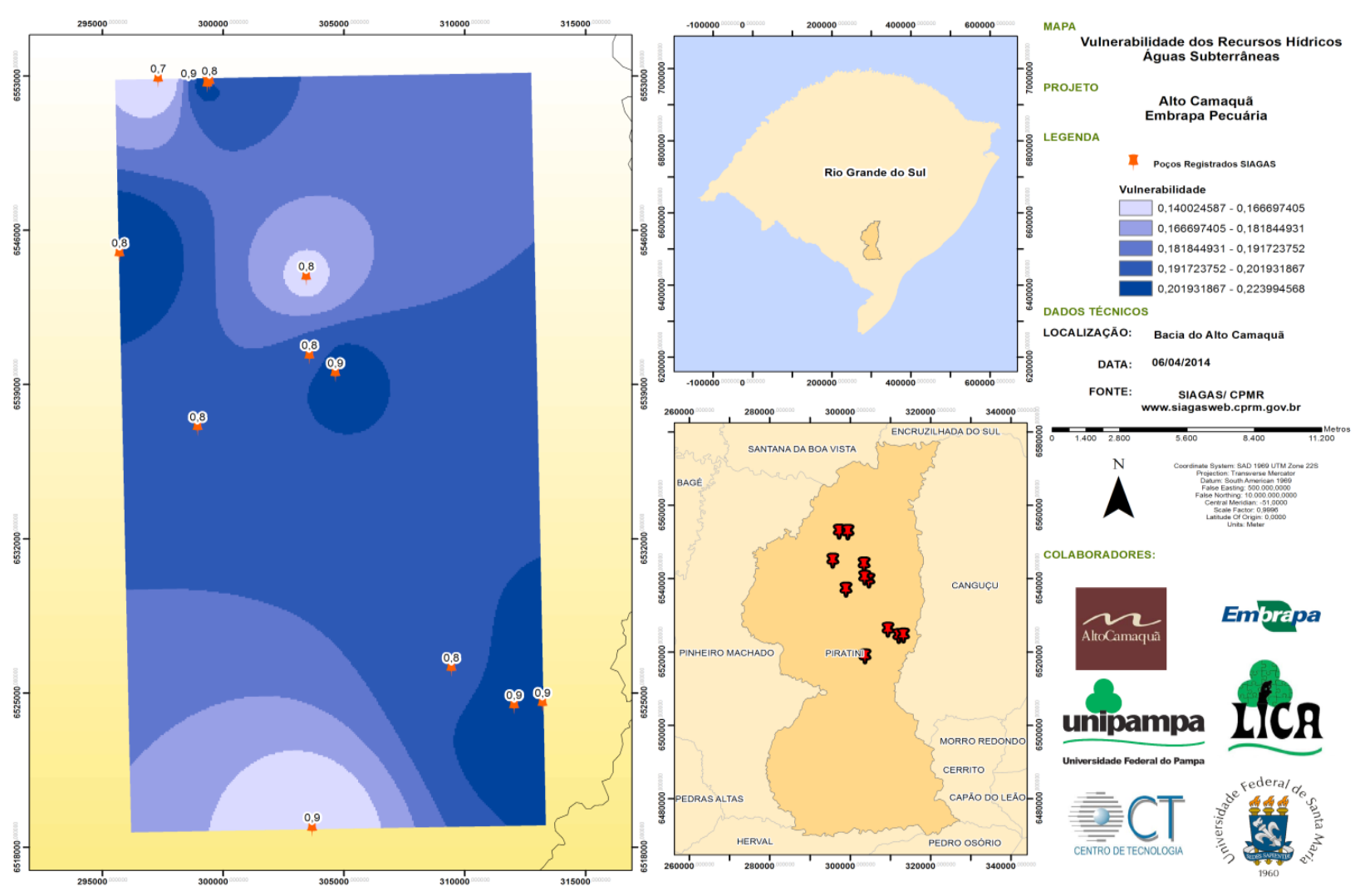

Figura 6: Mapa de Vulnerabilidade, no software ArcGis 10.

\section{DISCUSSÃO}

Dentre as principais fontes de contaminação indireta deveria ser feito um acompanhamento em postos de gasolina, cemitérios e possíveis contaminações com vazamento da rede de esgoto. Como geograficamente o fluxo de águas subterrâneas estaria alimentando o Rio Camaquã, qualquer tipo de contaminante seguiria o mesmo caminho. No entanto o município está localizado em uma área das cabeceiras da Bacia Hidrográfica do Rio Camaquã, mostrando assim, maiores preocupações topográficas e geológicas, pois a regiãoé pouco propícia a poços tubulares.

Além disso, obtêm expressivas quantidades de nascentes e afloramento necessitando assim de desenvolvimento de políticas de gerenciamento e planejamento ambiental adequado para controle do local de uso e ocupação do solo para a proteção dos recursos hídricos deste território.

\section{CONCLUSÃo}

Este trabalho teve o intuito de contribuir com a preservação ambiental e gerenciamento da zona de afloramentos da Bacia Hidrográfica do Rio Camaquã.

O município de Piratini possui, em grande maioria, zonas de captações de águas subterrâneas em áreas insignificantes e de baixa vulnerabilidade a contaminação devido à geologia da região. Tendo em vista a crescente área de soja e monocultura de árvores exóticas, além de agrotóxicos lançados na zona rural, deve-se manter um rigoroso controle para evitar que esses contaminantes cheguem ao aquífero.

A ferramenta "GOD" aplicada aos poços tubulares dos municípios é uma ferramenta necessária para o planejamento. Pode servir de base para planos e projetos como, por exemplo, planos diretores municipais e planejamentos rurais e ambientais. 
Ainda é necessário ter parcimônia com o licenciamento de todos os tipos possíveis de obras que utilizem o subsolo para disposição de resíduos e sua carga contaminante considerando as ocorrências de aquíferos fissurais.

Devido a sua formação litológica, com muitas variações, pode-se dizer que seria devido ao lençol freático, onde em zonas rurais do município exploram com legitimidade, (pois a água é um bem publico), as nascentes e afloramentos para abastecimento humano, que consequentemente, ficam expostos a contaminação em relação ao perímetro urbano. Recomenda-se a aplicação de outras metodologias de vulnerabilidade de aquíferos na região, principalmente, pela complexidade da Serra do Sudeste do Estado do Rio Grande do Sul, no qual, a comparação dos resultados bem como métodos de grau de confinamento de água subterrânea em cidades do território do Alto Camaquã e atualizações do cadastro de captações no Município e da região, pois, ainda existem poucos poços cadastrados, subsidiariam melhores políticas para a gestão de águas no município.

\section{REFERÊNCIA}

CARVALHO, C. M. Avaliação das nascentes do território do Alto Camaquã/RS. Resumo Simples. Congrega, $2012 b$

COMPANHIA DE PESQUISA DE RECURSOS MINERAIS, CPRM. Sistema de Informações de Águas Subterrâneas, SIAGAS. Banco de dados dos poços cadastrados em Piratini-RS. Disponível em: $<<$ http:// siagasweb.cprm.gov.br/layout/pesquisa_complexa.php >. Acesso em: 20 nov. 2013

DRH. Departamento de recursos hídricos. Disponível em: <http://www.sema.rs.gov.br> acessado em: 18 nov. 2013

FOSTER, S. HIRATA, R.; GOMES, D.; D’ELISA, M. Proteção da Qualidade da Água Subterrânea: um guia para empresas de abastecimento de água, órgãos municipais e agências ambientais. São Paulo: Servemar, 2006.

FOSTER, S. S. D. \& Hirata, R. C. A. 1988. Groundwater Pollution Risk Evaluation: the Methodology Using Available Data. Lima: CEPIS/PAHO/WHO. 78 p.

FOSTER, S. S. D. e HIRATA, R. C. A. Determinacion del Riesgo de Contaminacion de Águas Subterrâneas - una metodologia basada en datos existentes. $2^{a}$ Edição. Lima, Peru: Centro Panamericano de Ingenieria Sanitaria y Ciencias del Ambiente / Organizacion Mundial de La Salud, 1991. 81p.

FOSTER, S. S. D. e Hirata, R. C. A. Groundwater pollution risk assessment: a meth- odology using available data. WHO-PAHO/HPE-CEPIS Technical Manual, Lima, Peru. 81pp, 1988.

FOSTER, S. S. D.; HIRATA, R. Contaminación de las águas subterráneas. Organização Mundial de laSalud. Organização Panamericana de laSalud, Centro Panamericano de Ingenieria Sanitária y Ciências Del Ambiente. Lima, Peru, 1987.

FOSTER, S; HIRATA, R; GOMES, D; D’ELIA, M; PARIS, M. (2006). Proteção da Qualidade da Água Subterrânea: um guia para empresas de abastecimento de água, órgãos municipais e agências ambientais. São Paulo, Servemar. 104p.

KIRCHHEIM, Roberto Eduardo; AGRA, Sidnei G. Diagnóstico hidrogeológico do Estado do RS: uma ferramenta para o plano estadual de recursos hídricos. In: SIMPÓSIO BRASILEIRO DE RECURSOS HÍDRICOS, 19., 27 nov. - 01 dez. 2011, Maceió. Anais... Maceió: ABRH, dez. 2011.

MACHADO, J.L.F. 1998 Hidroestratigrafia química preliminar dos aqüíferos da Região Central do Rio Grande do Sul. In: Congresso Brasileiro De Águas Subterrâneas, 10. São Paulo,1998. Anais, ABAS. Disponível em: < http:// aguassubterraneas.abas.org/asubterraneas/article/download/22237/14582> Acesso em: 16 nov. 2013 
MANOEL FILHO, J. Água Subterrânea: Histórico e Importância. In: FEITOSA, F. A. C.; MANOEL FILHO, J. Hidrogeologia - conceitos e aplicações. Fortaleza: CPRM/REFO; LBHID-UFPE, p. 3-10. 2000.

MEDEIROS et al. Mapeamento da vulnerabilidade de parte da Bacia Sedimentar do Baixo Curso do rio Paraíba utilizando o método GOD. Anais XV Simpósio Brasileiro de Sensoriamento Remoto - SBSR, Curitiba, PR, Brasil, 30 de abril a 05 de maio de 2011, INPE p.3819.

SIAGAS (Sistema de Informações de Águas Subterrâneas). <http://siagas.cprm.gov. br/> Acesso em: 28 de jun. de 2010.

TRINDADE, J. P. P.; BORBA M. F. S.; LEFEVBRE, J. Território do Alto Camaquã: apresentação da cobertura vegetal do Alto Camaquã: junho de 2007. Bagé: Embrapa Pecuária Sul, 2010b. 13 p. (Embrapa Pecuária Sul. Documentos, 107).

TRINDADE, J. P. P.; BORBA, M. F. S.; LEFEVBRE, J. Vegetação do território do Alto Camaquã: obtenção, tratamento e classificação de imagens de satélite Landsat TM , Bagé: Embrapa Pecuária Sul, 2010a. 42 p. (Embrapa Pecuária Sul. Documentos, 106). 